\title{
Micro cutting force model of micro-jet induced by cavitation collapse in the ultrasonic field at micro- nano scale
}

Linzheng Ye ( $\nabla$ Iz09020141@163.com )

North University of China

Xijing Zhu

North University of China

Yan $\mathrm{He}$

North University of China

\section{Research Article}

Keywords: Ultrasonic cavitation, Micro-jet, Micro cutting force, Size effect

Posted Date: April 8th, 2021

DOl: https://doi.org/10.21203/rs.3.rs-401921/v1

License: (c) (1) This work is licensed under a Creative Commons Attribution 4.0 International License.

Read Full License

Version of Record: A version of this preprint was published at The International Journal of Advanced Manufacturing Technology on January 8th, 2022. See the published version at https://doi.org/10.1007/s00170-021-08402-7. 


\section{Abstract}

The micro-jet is the main mechanism of cavitation on materials. More and more ultrasonic cavitation assisted machining uses the micro-jet effect in the industrial field. In this paper, the micro-jet impact is considered as the micro cutting process. To deeply analyze the micro cutting mechanism of micro-jet, the size effect of materials was considered, and the micro cutting force model of micro-jet was established and solved based on the spherical indentation test theory and the strain gradient plasticity theory. The results showed that the micro cutting force and impact pressure of micro-jet with size effect are larger than those without size effect, and the micro cutting force of single micro-jet is within $2.35 \mathrm{~N}$. The micro cutting force of micro-jet increases exponentially with the increase of pit radius, but only slightly increases with the increase of pit depth. When the size effect is considered or not, the impact pressure of micro-jet is 1616-2922 MPa or 1615-1980 MPa, respectively. The increase ratio of micro cutting force with size effect is, which can directly reflect the strength of size effect. The size effect is more obvious when the pit size is smaller, and the maximum increase ratio is $47.54 \%$. The increase ratio increases nonlinearly with the decrease of pit radius and increases with the increase of pit depth. It has a strong correlation with pit radius and pit depth. This paper can provide a new theoretical viewpoint and support for the quantitative description of cavitation effect in ultrasonic assisted machining.

\section{Full Text}

This preprint is available for download as a PDF.

\section{Figures}
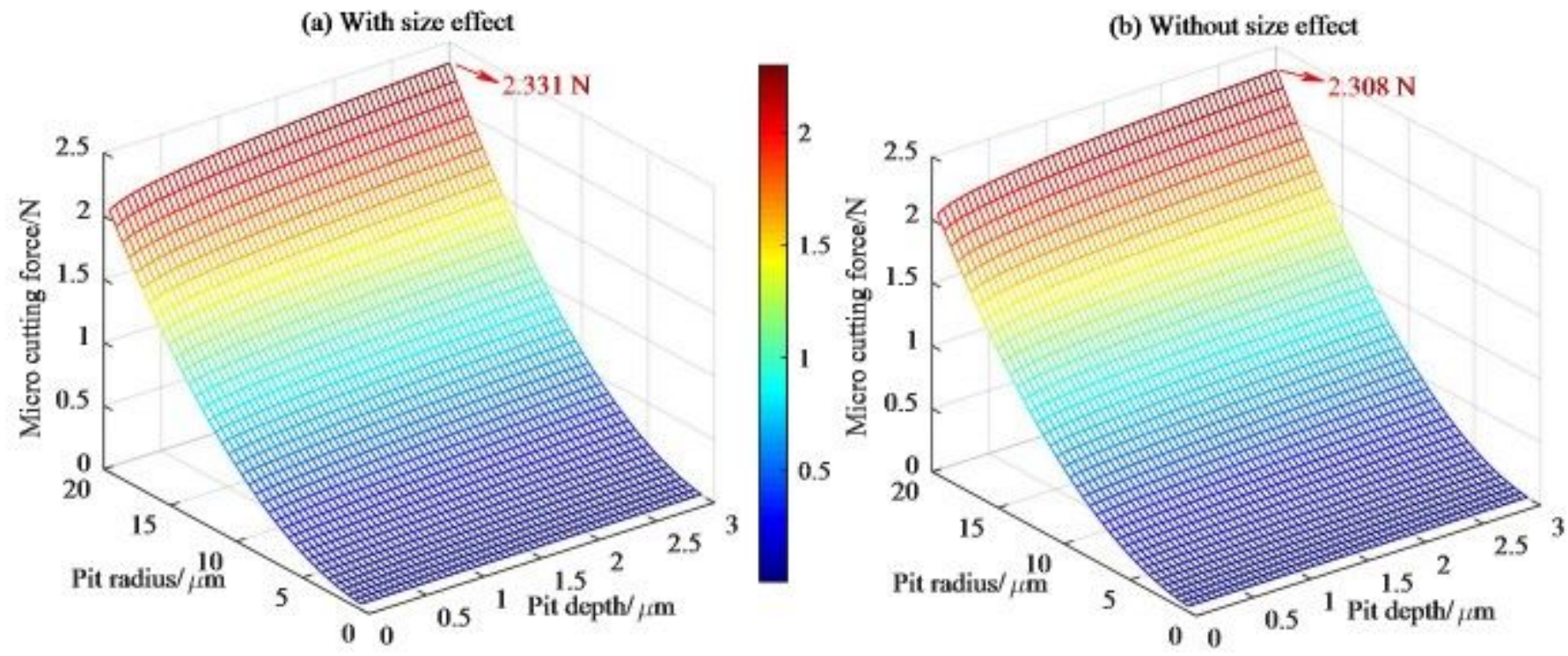

Figure 1 
Micro cutting force of micro-jet with different pit sizes ((a) with size effect (b) without size effect)

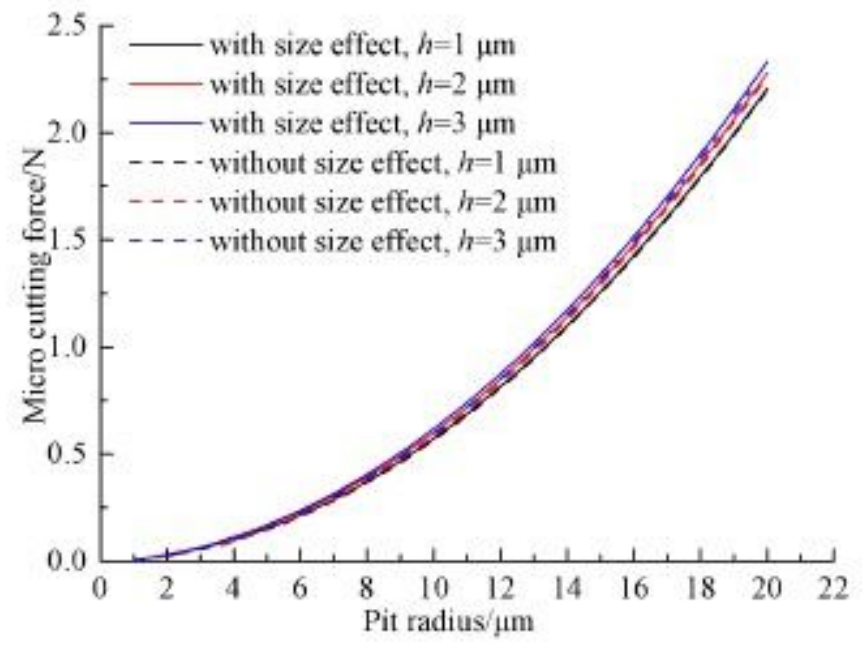

Figure 2

Variation curve of micro cutting force of micro-jet with pit radius

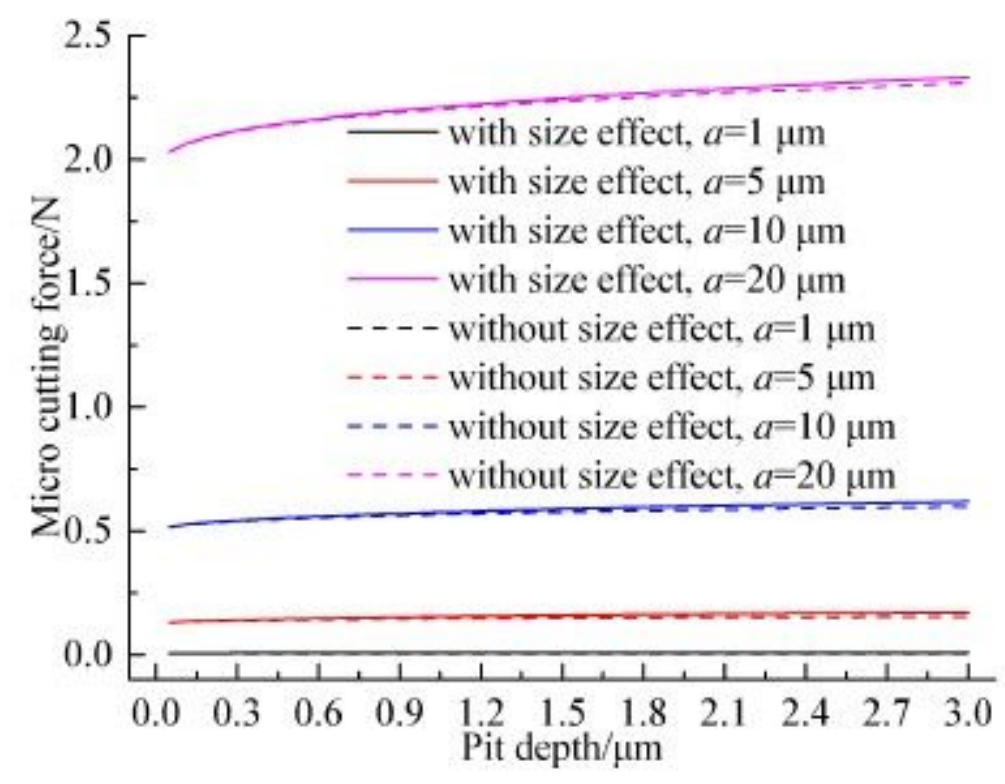

Figure 3

Variation curve of micro cutting force of micro-jet with pit depth 


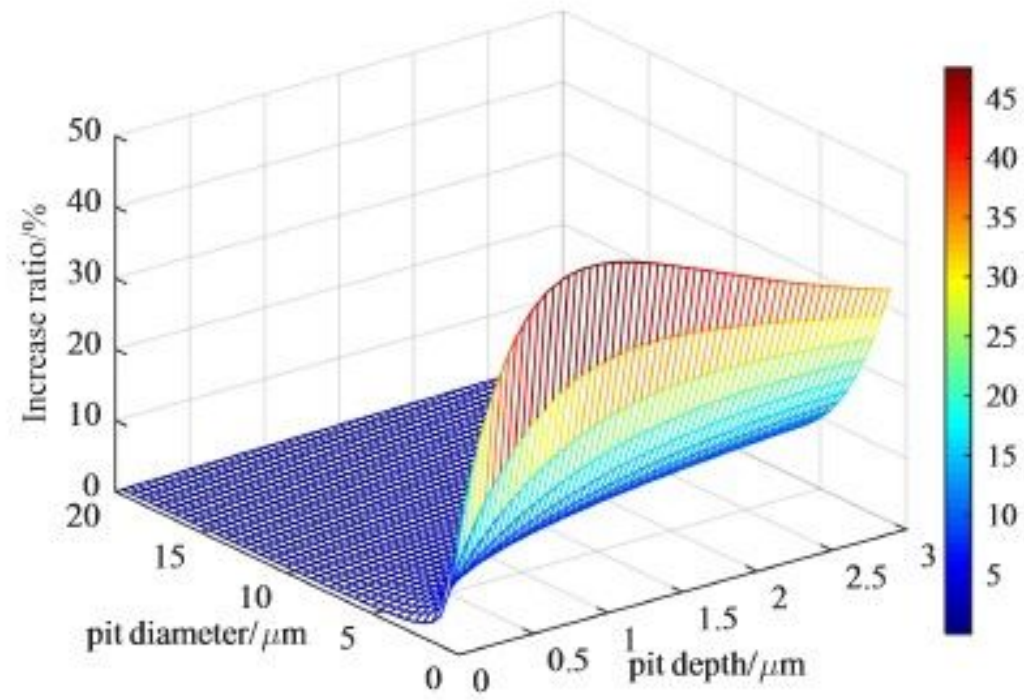

Figure 4

Increase ratio of different pit sizes

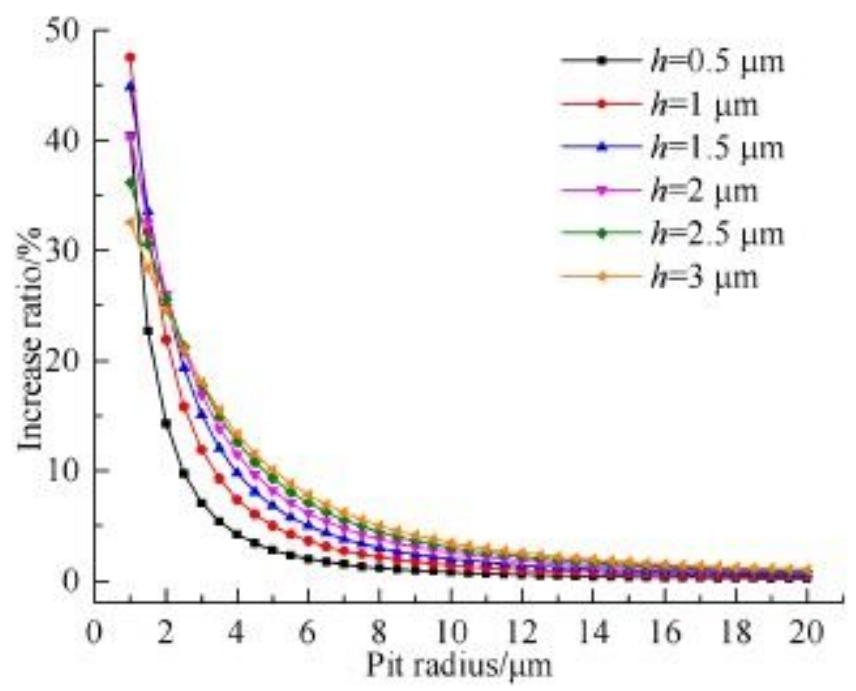

Figure 5

Variation curve of increase ratio with pit radius 


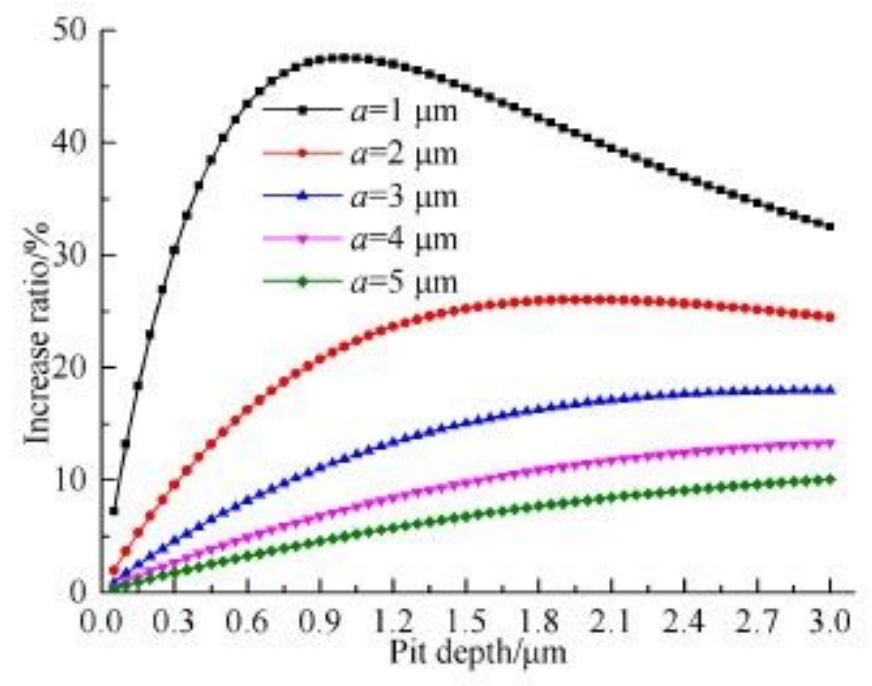

Figure 6

Variation curve of increase ratio with pit depth

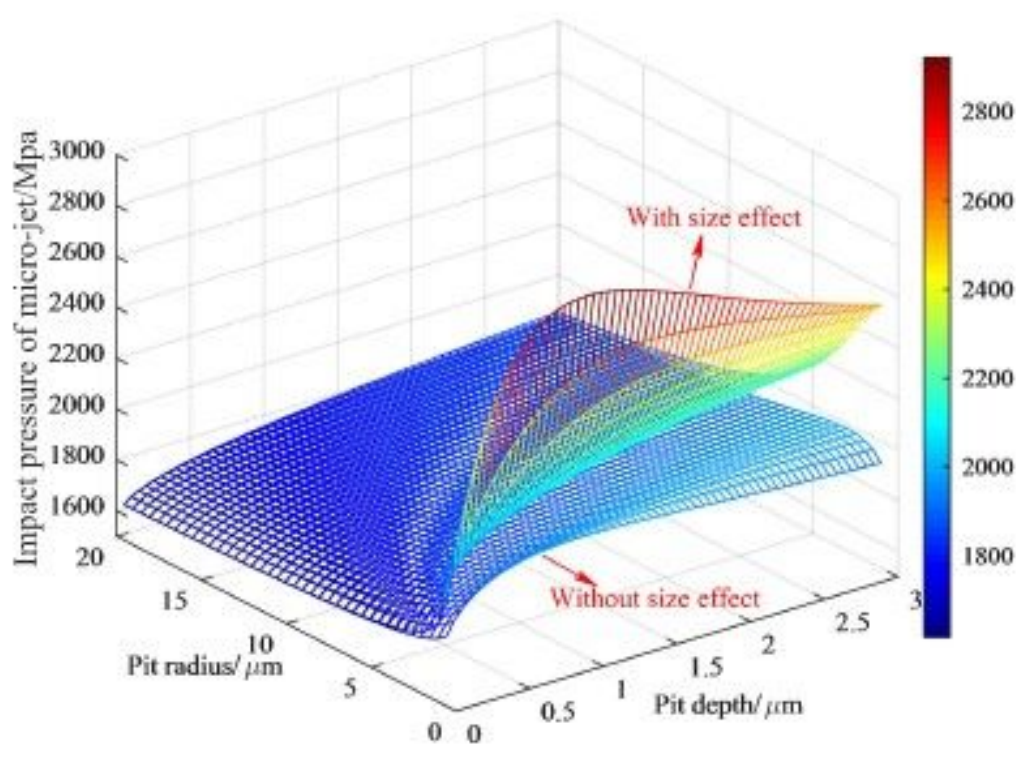

Figure 7

Impact pressure of micro-jet with different pit sizes 